\title{
Effect of Albendazole and Mebendazole on Hydatid Cyst of Mice
}

\author{
Ekram Ismail Fagiree Ismail ${ }^{1}$, Mohammed Bahaa Eldeen Ahmed Saad ${ }^{2}$, Aisha Abass Elsadig ${ }^{3}$ \\ ${ }^{1}$ Department of Biology, Alzaem Alazhari University, Khartoum, Sudan \\ ${ }^{2}$ Alahlia University, Khartoum, Sudan \\ ${ }^{3}$ Department of Radioisotopes of the Veterinary Research Center, Khartoum, Sudan \\ Email: ik_fagiree@hotmail.com
}

How to cite this paper: Fagiree, E.I., Saad, B.M. and Elsadig, A.A. (2017) Effect of Albendazole and Mebendazole on Hydatid Cyst of Mice. Open Journal of Epidemiology, 7, 307-316.

https://doi.org/10.4236/ojepi.2017.74025

Received: April 11, 2017

Accepted: October 14, 2017

Published: October 17, 2017

Copyright ( $) 2017$ by authors and Scientific Research Publishing Inc. This work is licensed under the Creative Commons Attribution International License (CC BY 4.0).

http://creativecommons.org/licenses/by/4.0/

(c) (i) Open Access

\begin{abstract}
In the current study, hydatid cysts from livers and lungs of camels were obtained from Tambool slaughter house and protoscoleces were separated aseptically. 36-weeks-old Swiss mice (25 - 30 gram body weight males and females) were divided into two groups of 6 each: a prophylactic group dosed with $150 \mathrm{ml} / \mathrm{kg}$ of albendazole and mebendazole was given directly after injection with 2000 protoscoleces intraperitoneally for 10 consecutive days. The treated group was given a dose of $300 \mathrm{ml} / \mathrm{kg}$ of albendazole and mebendazole for 24 days with 4 days interval separated by 2 days and after 6 months of inoculation with protoscoleces, the two groups in addition to the control group were sacrificed and necropsied. The results revealed a significant difference in the development of hydatid cyst $(p<0.01)$. Inside the mice, small number of cysts was noticed in the group treated with albendazole and mebendazole compared to the control group, however, albendazole was highly efficacious than the mebendazole where the efficiency of albendazole reached $97 \%$ while the mebendazole efficiency rate was almost $50 \%$ which indicates that albendazole could be considered the drug of choice in the treatment of hydatid cyst.
\end{abstract}

\section{Keywords}

Hydatid Cyst, Mebendazole, Albendazole

\section{Introduction}

Cystic echinococcosis (CE) caused by the metacestode (larval) stage of Echinococcus. granulosus is still an important public health concern in many countries of the world, such as the Mediterranean and South American countries as the disease affects humans and domestic livestock including cattle, sheep, camels, 
pigs, horses and others [1]. In the early 1970s, benzimidazole methylcarbamates derivatives (BZD) were proved to be effective against E. granulosus, and since then, many investigators have used albendazole (ABZ) and mebendazole (MBZ) for the treatment of human hydatidosis [2]. Albendazole and mebendazole are considered to be equally effective. When evaluated up to 12 months after initiation of benzimidazole treatment, $10 \%-30 \%$ of patients show cyst disappearance, $50 \%-70 \%$ show degeneration of cysts and $20 \%-30 \%$ show no morphological changes in the cyst appearance. Continuous or intermittent treatment with albendazole is recommended for a period of 6 months [3]. At present time, benzimidazole methylcarbamate compounds such as albendazole and mebendazole have been used to treat $\mathrm{CE}$ in humans [4]. Mebendazole was the first compound widely used [5]. Although effective, the main disadvantage was the extremely high doses and prolonged administration period required to achieve a satisfactory clinical efficacy. Albendazole was therefore a major breakthrough because, while absorption of the parent compound remained poor, its metabolite, albendazole-sulphoxide (ABZSO) was shown to be an active anthelmintic agent [6]. Both $\mathrm{ABZ}$ and $\mathrm{ABZSO}$ have been shown to be active against protoscolices of $E$. granulosus in in vitro culture systems. However, the in vitro protoscolicidal action of $\mathrm{ABZ}$ and $\mathrm{ABZSO}$ is very slow and requires a longer incubation period compared to that observed for MBZ [7]. In vitro and in vivo differences in the protoscolicidal activity of BZD anthelmintics have been observed. The significance of the effects of albendazole, mebendazole has been discussed by a few researchers [8] [9] [10]. [11] had concluded that albendazole and povidoneiodine are effective for the killing of hydatid protoscoleces and inhibit hydatid cyst development.

Long term daily albendazole treatment after surgical resection of the cyst masses, has suppressed parasite growth in some dogs with Echinococcus. multilocularis cysts [12].

\section{Materials and Methods}

The field work was conducted in Tambool area (Central Eastern Sudan) where slaughtered camels were checked for hydatid cysts. Laboratory work was performed at the laboratories of the Faculty of Education, Alzaem Alazhari University and the Faculty of Education, University of Khartoum.

The study included camels slaughtered at Tambool market using white mice (25 - 30 gram body weight males and females) which were obtained from Veterinary Research Center, Soba, Khartoum for experimental purposes.

One hundred fifty slaughtered camels in Tambool market were thoroughly inspected for the presence of hydatid cysts in different organs. Hydatid cysts, when found were counted. The size of the cysts was measured using an ordinary ruler [13]. Aspiration of cyst fluid was made for detection of fertility or sterility status of the cysts.

Three parasitological parameters were considered when a cyst was found. 
These were measuring the cyst size, status of cyst fluid, and viability of the cyst.

Protoscoleces were collected under aseptic conditions from hydatid cysts obtained from camels. Viability of the protoscoleces was confirmed by visual inspection through inverted microscope. The protoscoleces were resuspended with water and 2000 of protoscoleces were inoculated intraperitoneally in each mice (30 weeks of age). Male and female mice weighing 25 - 30 g were used. Thirty mice were inoculated with protoscoleces of hydatid cyst and divided into 5 groups of 6 mice each. Two prophylactic groups, immediately after being inoculated with protoscoleces, received $150 \mathrm{mg} / \mathrm{kg}$ bw/day albendazole (group 1) and mebendazole (group 2) orally for 10 days. Two other groups (treatment groups) received oral treatment 6 months after inoculation with protoscoleces with 300 $\mathrm{mg} / \mathrm{kg}$ of albendazole (group 3) and mebendazole (group 4) every 4 days with an interval of 2 days for totally 24 treatment days (six times). The fifth group of mice remained as the untreated control. All mice were scarified after 7 months and internal organs were observed for the presence of hydatid cyst.

The efficacy rate was determined using the formula:

$\frac{\text { Number of cyst in the control group }- \text { Number of cyst in the treated group }}{\text { Number of cyst in the control group }} \times 100$

Statistical Analysis: The data were analyzed using SPSS program (version10) and Excel application. Results were considered, Non significant at $p>0.05$, significant at $p<0.05$, highly significant at $p<0.01$.

\section{Results}

It is to be revealed that all mice were sacrificed 7 month after inoculation for all groups (prophylactic, treated and control group). In group one (prophylactic), which received $150 \mathrm{mg}$ albendazole for 10 days, 8 cysts were counted for all the mice showing an efficiency rate of $70 \%$ compared to that of the control group. All the cysts encountered were of the small size and located either in the liver or peritoneal cavity (Table 1 (a) and Table 1 (b), Figure 1). In group 2 (prophylactic) which received $150 \mathrm{mg}$ mebendazole for 10 days, 19 cysts were counted for all the mice showing an efficiency rate of $42 \%$ compared to that of the control group. All cysts encountered were of the small size and located either in the liver or peritoneal cavity (Table 1 (a) and Table 1(b), Figures 2-4). In group 3 (treated) which received treatment with $300 \mathrm{mg}$ albendazole for 24 days, only one small cyst in the peritoneal cavity was encountered showing an efficiency rate of 97\% (Table 2(a) and Table 2(b), Figure 5). In Group 4 (treated) which received $300 \mathrm{mg}$ mebendazole for 24 days, 9 cysts were counted showing an efficiency rate of $73 \%$ (Table 2 (a) and Table 2(b), Figures 6-8). All of the cysts were small size and located in the liver or peritoneal cavity, 3 cyst were observed in the lung and subcutaneous tissues. In the control group, 33 cysts were counted, all of the medium size. As expected, the majority of cysts were fertile (Table 3 and Figure 9 and Figure 10). 
- of mice \# $\quad$ of cyst \#

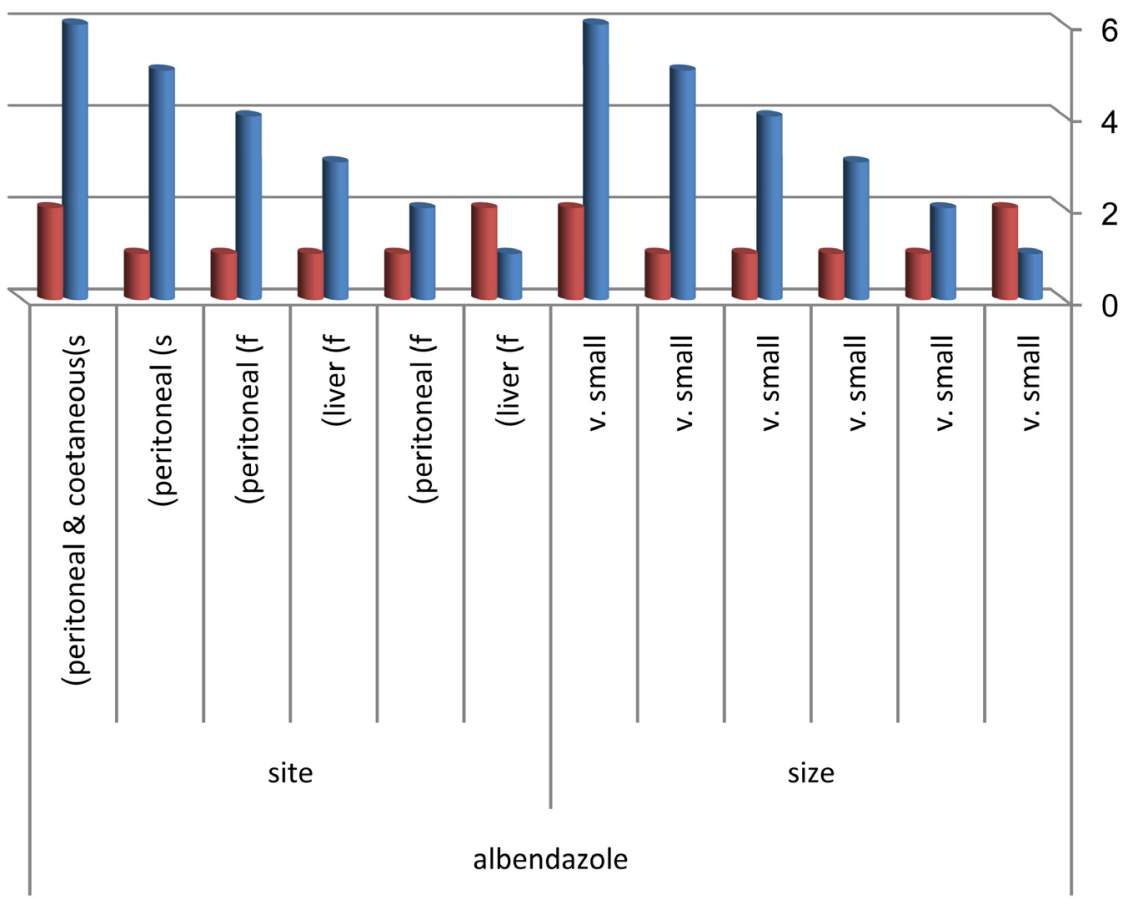

Figure 1. In vivo effect of albendazole on hydatid cyst of mice (prophylactic group).

Table 1. (a) In vivo effect of albendazole and mebendazole on hydatid cyst of mice (prophylactic group); (b) The efficiency rate of albendazole and mebendazole in prophylactic group.

(a)

\begin{tabular}{ccccccc}
\hline \multirow{2}{*}{$\begin{array}{c}\text { Mice } \\
\text { No. }\end{array}$} & \multicolumn{3}{c}{ Albendazole } & \multicolumn{4}{c}{ Mebendazole } \\
\cline { 2 - 7 } & $\begin{array}{c}\text { No. of } \\
\text { cyst }\end{array}$ & site & size & $\begin{array}{c}\text { No. of } \\
\text { cyst }\end{array}$ & site & size \\
\hline 1 & 2 & liver & v small & 3 & liver \& peritoneal (f) & Small \\
2 & 1 & peritoneal (f) & v small & 1 & peritoneal (f) & Small \\
3 & 1 & liver & v small & 5 & liver \& peritoneal (f) & Small \\
4 & 1 & peritoneal (f) & v small & 5 & liver \& peritoneal (f) & Small \\
5 & 1 & peritoneal (f) & v small & 4 & liver \& peritoneal (f) & Small \\
6 & 2 & peritoneal \& coetaneous (s) & v small & 1 & liver (f) & Small \\
Total & 8 & & & 19 & & \\
\hline
\end{tabular}

V: Very. F: Fertile. S: Sterile.

(b)

\begin{tabular}{cccc}
\hline Groups & No. of cyst & Size & Efficiency $\%$ \\
\hline Albendazole & 8 & small & $70 \%$ \\
Mebendazole & 19 & small & $42 \%$ \\
Control & 33 & & $100 \%$ \\
\hline
\end{tabular}




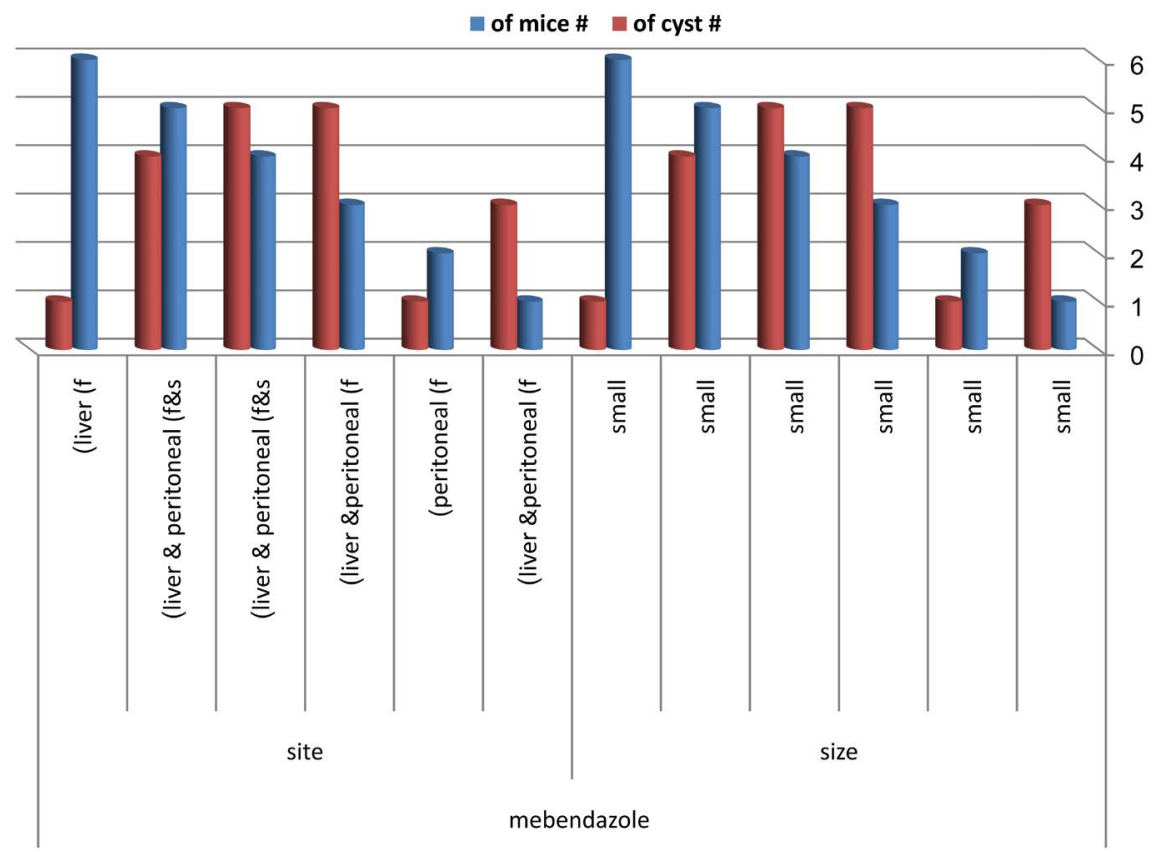

Figure 2. In vivo effect of mebendazole on hydatid cyst of mice (prophylactic group).

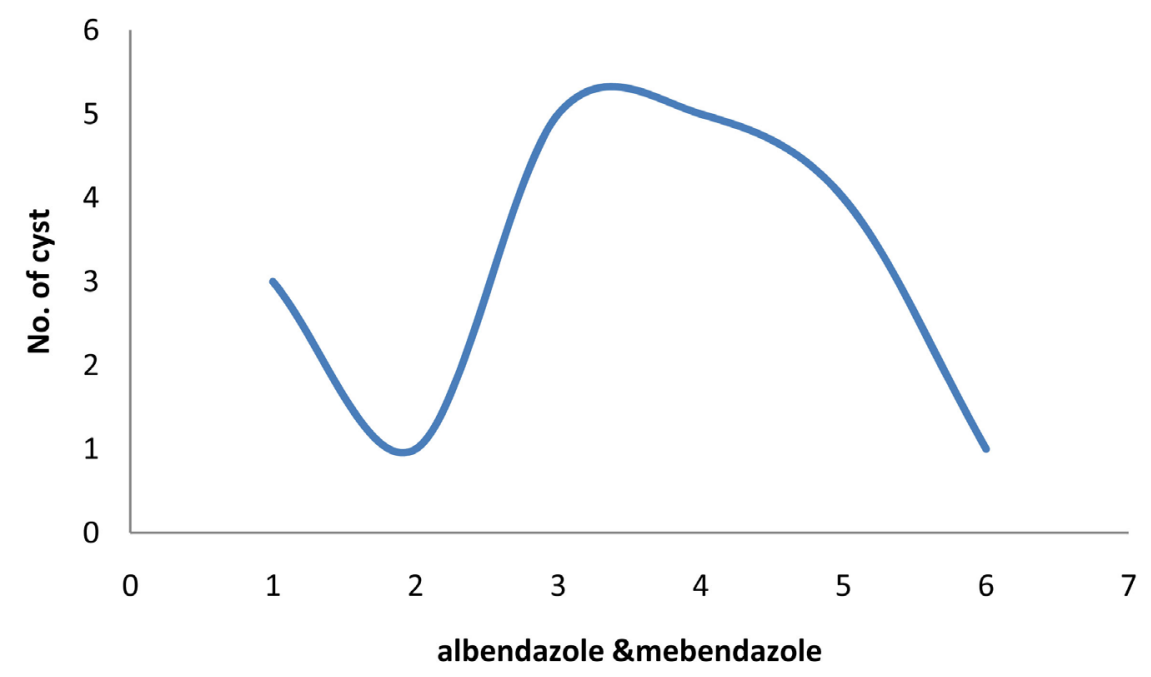

Figure 3. Prophylactic group.

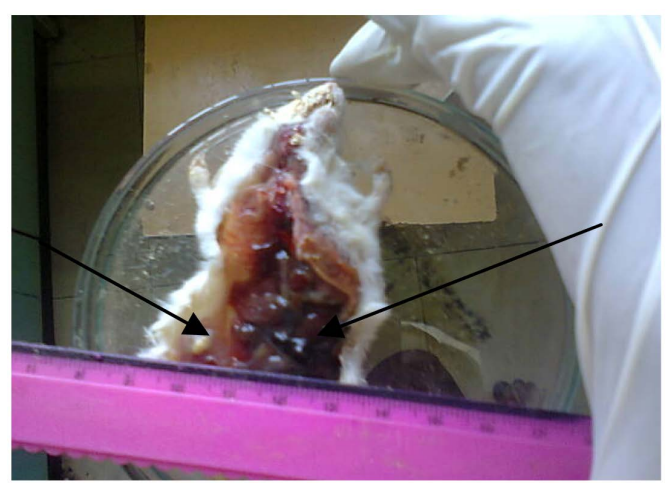

Figure 4. Cysts in prophylactic group (Mebendazole). 


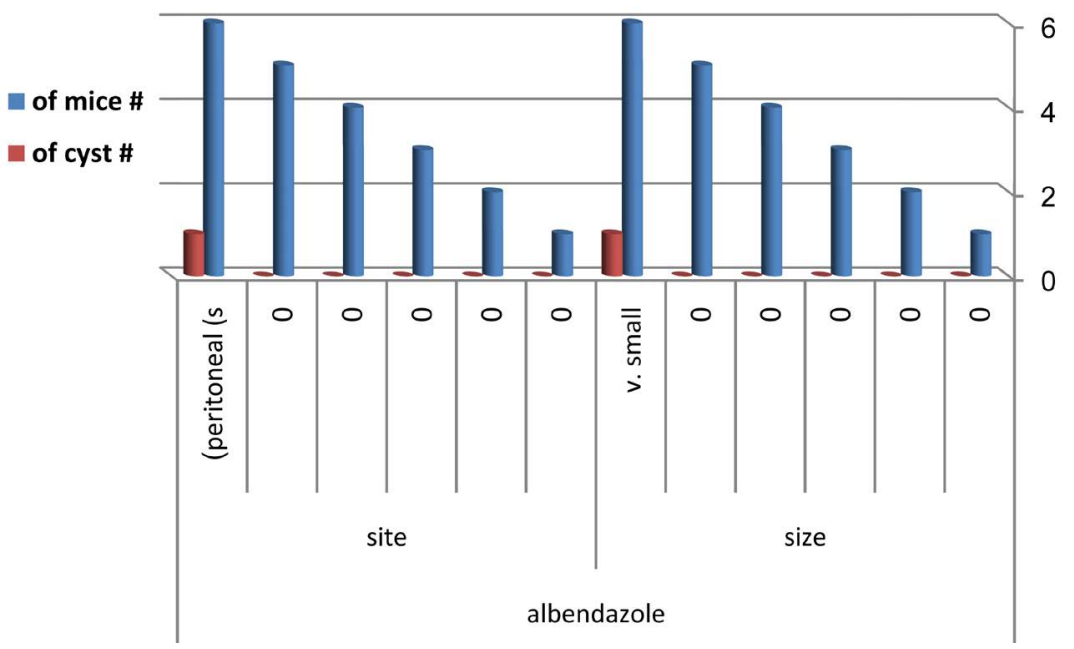

Figure 5. In vivo effect of albendazole on hydatid cyst of mice (treated group).

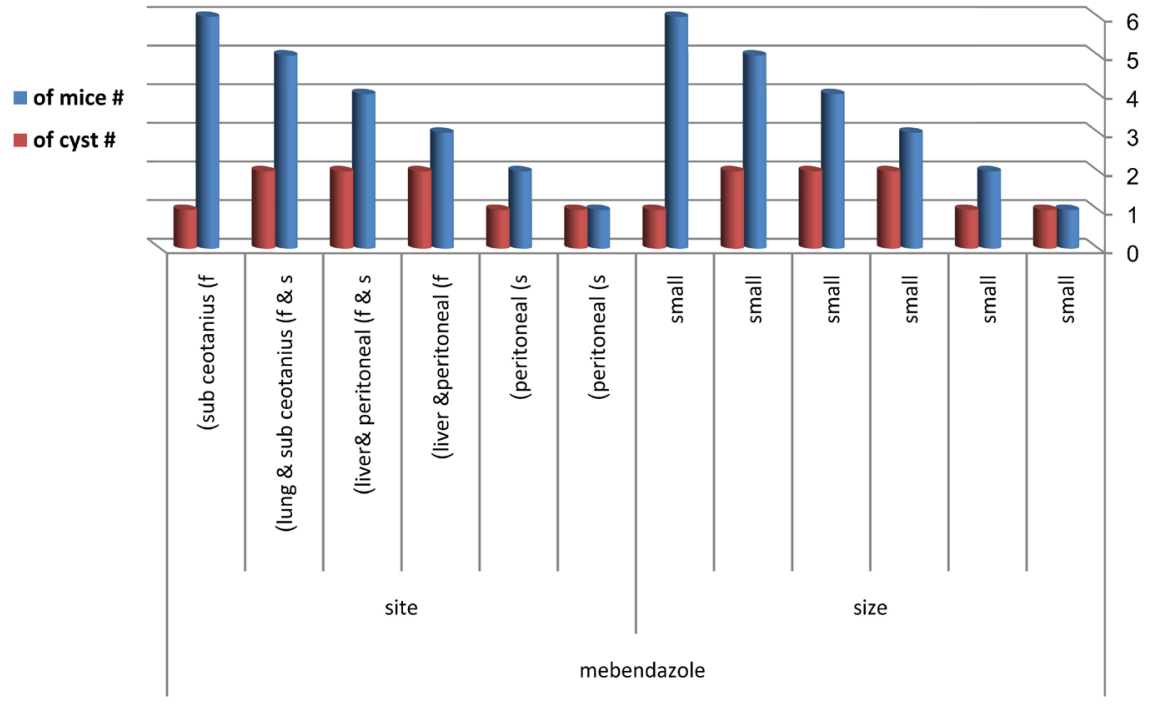

Figure 6. In vivo effect of mebendazole on hydatid cyst of mice (treated group).

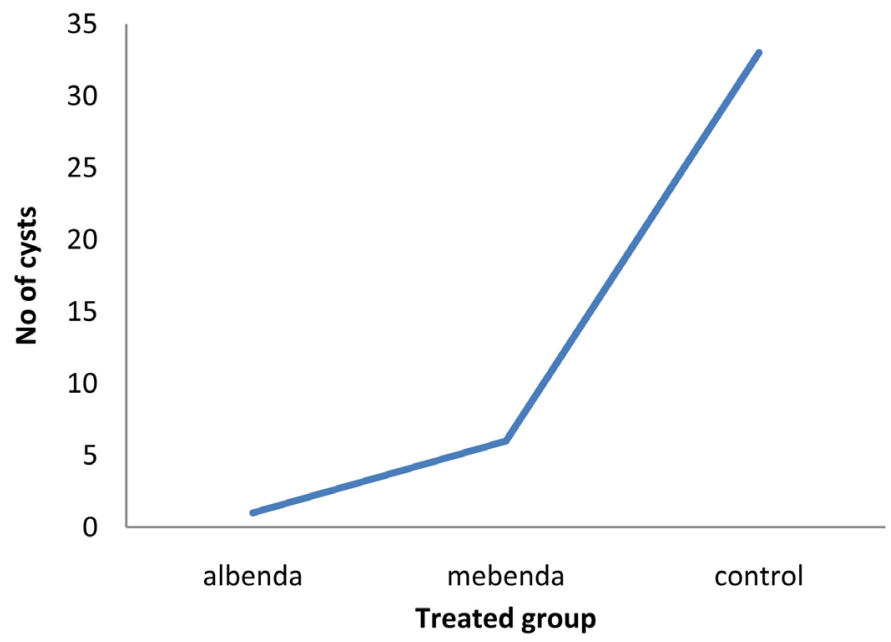

Figure 7. Treated groups. 


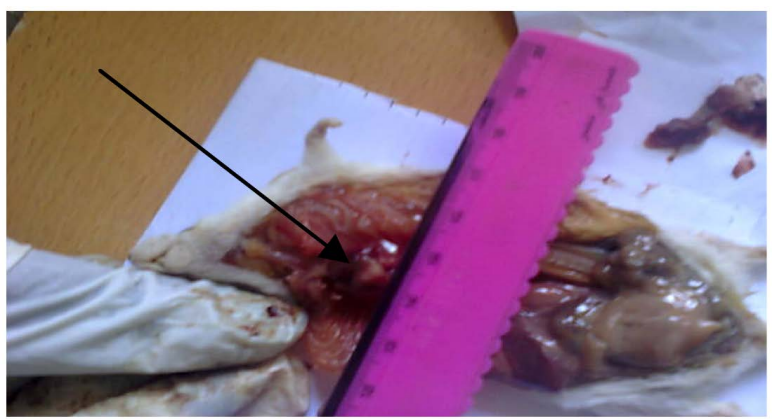

Figure 8. Cysts in treated group with mebendazole.

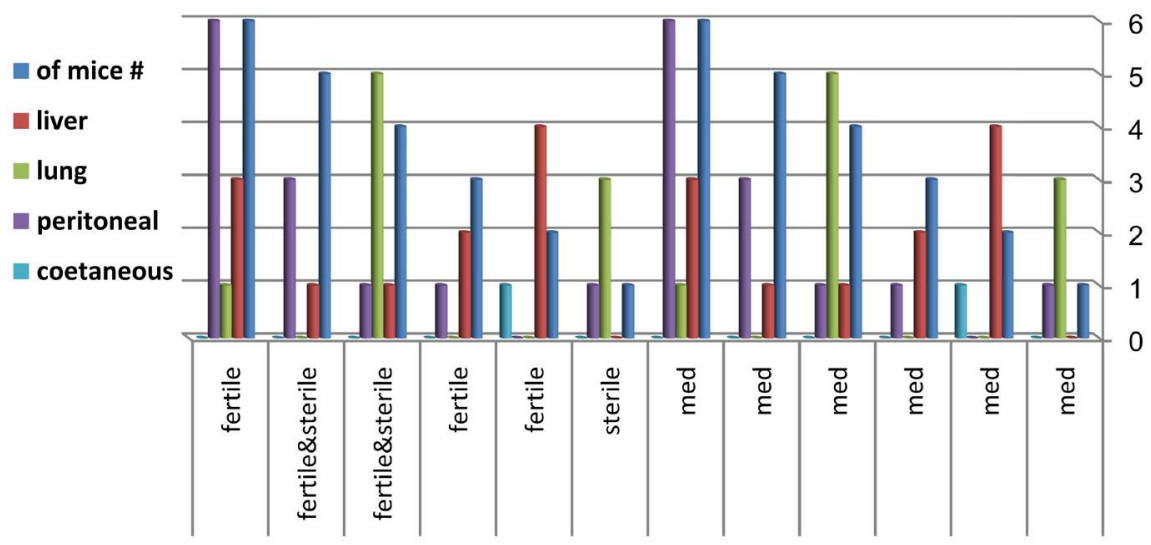

Figure 9. In vivo effect of albendazole and mebendazole on hydatid cyst of mice (control group).

Table 2. (a) In vivo effect of albendazole and mebendazole on hydatid cyst of mice (treated group); (b) The efficiency rate of albendazole and mebendazole in treated group.

(a)

\begin{tabular}{ccccccc}
\hline \multirow{2}{*}{ No of mice } & \multicolumn{3}{c}{ Albendazole } & \multicolumn{4}{c}{ Mebendazole } \\
\cline { 2 - 7 } & No. of cyst & site & size & No of cyst & site & size \\
\hline 1 & 0 & - & - & 1 & peritoneal (s) & Small \\
2 & 0 & - & - & 1 & peritoneal (s) & Small \\
3 & 0 & - & - & 2 & liver \& peritoneal (f) & Small \\
4 & 0 & - & - & 2 & liver \& peritoneal (f) & Small \\
5 & 0 & - & - & 2 & lung \& sub (f \& s) & Small \\
6 & 1 & peritoneal (s) & v small & 1 & sub ceotanius (f) & Small \\
Total & 1 & & & 9 & & \\
\hline
\end{tabular}

V: Very. F: Fertile. S: Sterile.

(b)

\begin{tabular}{cccc}
\hline Groups & No. of cyst & Size & Efficiency $\%$ \\
\hline Albendazole & 1 & Small & $97 \%$ \\
Mebendazole & 9 & Small & $73 \%$ \\
Control & 33 & Medium & $100 \%$ \\
\hline
\end{tabular}




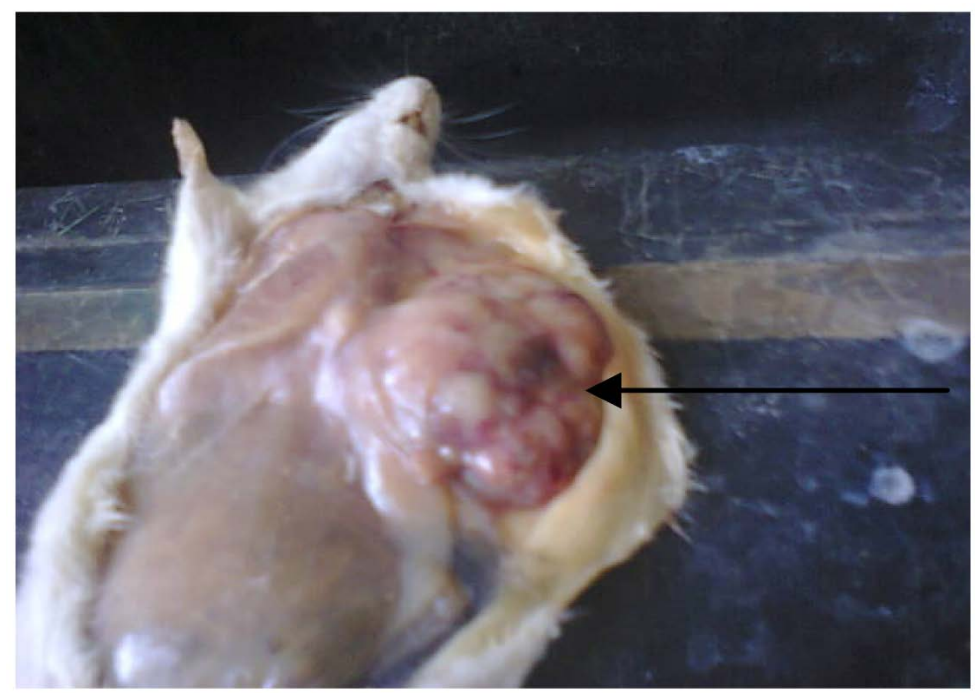

Figure 10. Cysts in control group.

Table 3. In vivo effect of albendazole and mebendazole on hydatid cyst of mice (control group).

\begin{tabular}{ccccccc}
\hline No of Mice & size & liver & lung & peritoneal & coetaneous & case \\
\hline 1 & medium & 0 & 3 & 1 & 0 & sterile \\
2 & medium & 4 & 0 & 0 & 1 & fertile \\
3 & medium & 2 & 0 & 1 & 0 & fertile \\
4 & medium & 1 & 5 & 1 & 0 & fertile \& sterile \\
5 & medium & 1 & 0 & 3 & 0 & fertile \& sterile \\
6 & medium & 3 & 1 & 6 & 0 & fertile \\
Total & medium & 11 & 9 & 12 & 1 & \\
\hline
\end{tabular}

\section{Discussion}

In the present study, the efficacy of albendazole and mebendazole in the treatment of hydatid cyst in mice was investigated. The results showed that when mice were treated with albendazole, no cysts were found in internal organs, while treatment with mebendazole showed many cysts in internal organs, which indicates that albendazole, is more effective than mebendazole. Our finding was consistent with the finding of [14] [15] [16] who reported that continuous long term albendazole therapy in animal models is parasiticidal against larval stage of E. multilocularis especially in the early stages of infection. Our findings are also in line with the work of [17] who evaluated the effect of albendazole on hydatid cysts of human. Twenty-nine patients with 240 cysts received albendazole (400 $\mathrm{mg}$ twice a day, in 3 cycles of 6 weeks long with 2 weeks off between cycles). Some patients with liver cysts after treatment showed increasing heterogeneity and density suggestive of inactive cysts. Patients with larger cysts and those with pulmonary involvement were better responders. The observed results are encouraging, showing high efficacy of albendazole for the treatment of hydatidosis 
and should be offered to patients as an alternative before surgical treatment is considered. Another experiment by Daniel, M. et al. [18] compared two different preparations (solution and suspension) of three benzimidazole carbamate drugs (mebendazole, albendazole \& ricobendazole) were compared by analyzing their activities against Echinococcus granulosus cysts in mice. The effect was more prominent on mebendazole-treated mice, at doses of $25-50 \mathrm{mg} / \mathrm{kg}$. It has been reported by [14] that although mebendazole, the first benzoimidazole used, has some beneficial effects on the disease in selected patients, it has also been associated with treatment failure in some cases, perhaps because of its poor absorption. It has been shown by [19] that hydatid cysts were severely damaged in mice treated with mebendazole and new vesicles did not develop around the damaged ones. In another experiment by [20], indicated that the postoperative prophylactic course of mebendazole is reliable, safe and with minor side effects and the recurrence rate of the disease was reduced to the lowest possible levels. The results of the above experiments with mebendazole were not consistent with our results which proved high efficiency rate of elbendazole compared with that of mebendazole.

\section{Acknowledgements}

The authors wish to thank Mr. Sofian Albasheer for providing help in statistics of the study, thank Miss Suad Fagiry for supply and thanks are extended to Mr. Mohammed Osman and Mr. Abdorahman Dahees. Our thanks are also extended to the technical staff of the department of histopathology, faculty of Medical Laboratory sciences, Al Zaeim Al Azhari University for their technical assistance.

\section{References}

[1] Torgerson, P.R. and Budke, C.M. (2003) Echinococcosis-An International Public Health Challenge. Research in Veterinary Science, 74, 191-202. https://doi.org/10.1016/S0034-5288(03)00006-7

[2] Teggi, A., Lastilla, G.M. and De Rosa, F. (1993) Therapy of Human Hydatid Disease with Mebendazole and Albendazole. Antimicrobial Agents and Chemotherapy, 37, 1679-1684. https://doi.org/10.1128/AAC.37.8.1679

[3] Kern, P. (2003) Echinococcus Granulosus Infection: Clinical Presentation, Medical Treatment and Outcome. Langenbecks Archives in Surgery, 388, 13-20.

[4] El-On, J. (2003) Benzimidazole Treatment of Cystic Echinococcosis. Acta Tropical, 85, 243-252. https://doi.org/10.1016/S0001-706X(02)00217-6

[5] Bekhti, A., Schaaps, J.P., Capron, M., Dessaint, J.P., Santoro, F. and Capron, A. (1977) Treatment of Hepatic Hydatid Disease with Mebendazole: Preliminary Results in Four Cases. British Medical Journal, 2, 1047-1051. https://doi.org/10.1136/bmj.2.6094.1047

[6] Horton, J. (2003) Albendazole for the Treatment of Echinococcosis. Fundamental and Clinical Pharmacology, 17, 205-212. https://doi.org/10.1046/j.1472-8206.2003.00171.x

[7] Pérez-Serrano, J., Casado, N., Denegri, G. and Rodríguez-Caabeiro, F. (1994) The 
Effects of Albendazole and Albendazole Sulphoxide Combination Therapy on Echinococcus Granulosus In Vitro. International Journal of Parasitology, 24, 219-224. https://doi.org/10.1016/0020-7519(94)90029-9

[8] Pérez-Serrano, J., Martínez, J., Denegri, G., Casado, N., Bodega, G. and Rodríguez-Caabeiro, F. (2001) In Vitro Effect of Albendazole and Albendazole Sulphoxide on 70 and $60 \mathrm{kDa}$ Heat Shock Proteins in Echinococcus Granulosus Protoscolices. Research and Reviews in Parasitology, 61, 67-71.

[9] Rodríguez-Caabeiro, F., Casado, N. and Juárez-Peláez, E. (1989) Effect In Vitro of Praziquantel, Mebendazole Oxfendazole on Protoescolices of Echinococcus Granulosus. Review of Parasitology, 49, 77-83.

[10] Stettler, M., Rossignol, J.F., Fink, R., Walker, M., Gottstein, B., Merli, M., Theurillat, R., Thormann, W., Dricot, E., Segers, R. and Hemphill, A. (2004) Secondary and Primary Murine Alveolar Echinococcosis: Combined Albendazole/Nitazoxanide Chemotherapy Exhibits Profound Anti-Parasitic Activity. International Journal Parasitology, 34, 615-24. https://doi.org/10.1016/j.ijpara.2004.01.006

[11] Polat, E., Aslan, M., Cakan, H., Saribas, S., Ipek, T. and Kocazeybek, B. (2009) The Effects of Albendazole and Povidone Iodine for Hydatid Cysts Protoscoleces, in Vitro and in Vivo. African Journal of Microbiology Research, 3, 743-746.

[12] WHO/OIE (2011) Manual on Echinococcosis in Humans and Animals, a Public Health Problem of Global Concern. Acta Trop.

[13] Gibson, T.E. (1969) Biology of Hydatidosis. Veterinary Record, 85, 320-322. https://doi.org/10.1136/vr.85.12.320

[14] Anadol, D., Ozçelik, U., Kiper, N. and Göçmen, A. (2001) Treatment of Hydatid Disease. Pediatric Drugs, 3, 123-135. https://doi.org/10.2165/00128072-200103020-00005

[15] Schipper, H.G. and Kager, P.A. (2004) Diagnosis and Treatment of Hepatic Echinococcosis: An Overview. Scandinavian Journal of Gastroenterology, No. 241, 50-55. https://doi.org/10.1080/00855920410011004

[16] Shaw, J.M., Bornman, P.C. and Krige, J.E. (2006) Hydatid Disease of the Liver. South African Journal of Surgery, 44, 70-72, 74-77.

[17] Keshmiri, M., Baharvahdat, H., Fattahi, S.H., Davachi, B., Dabiri, R.H., Baradaran, H. and Rajabzadeh, F. (2001) Albendazole versus Placebo in Treatment of Echinococcosis. Transactions of the Royal Society of Tropical Medicine and Hygiene, 95, 190-194.

[18] Daniel-Mwuambete, K., Ponce-Gordo, F., Torrado, J., Torrado, S. and Cuesta-Bandera, C. (2003) Effect of Two Formulations of Benzimidazole Carbamates on the Viability of Cysts of Echinococcus granulosus In Vivo. Parasitology, 10, 371-373.

[19] Nakaya, K., Oomori, Y., Kutsumi, H. and Nakao, M. (1998) Morphological Changes of Larval Echinococcus multilocularis in Mice Treated with Albendazole or Mebendazole. Journal of Helminthology, 72, 349-354. https://doi.org/10.1017/S0022149X00016722

[20] Ammari, F.F. and Omari, A.K. (2002) Surgery and Postoperative Mebendazole in the Treatment of Hydatid Disease. Saudi Medical Journal, 23, 568-571. 